\title{
Liquid metal embrittlement susceptibility of ferritic-martensitic steel in liquid lead alloys
}

\author{
J. Van den Bosch *, R.W. Bosch, D. Sapundjiev, A. Almazouzi \\ SCK-CEN (Belgian Nuclear Research Centre), Boeretang 200, B-2400 Mol, Belgium
}

\begin{abstract}
The susceptibility of the ferritic-martensitic steels T91 and EUROFER97 to liquid metal embrittlement (LME) in lead alloys has been examined under various conditions. T91, which is currently the most promising candidate material for the high temperature components of the future accelerator driven system (ADS) was tested in liquid lead bismuth eutectic (LBE), whereas the reduced activation steel, EUROFER97 which is under consideration to be the structural steel for fusion reactors was tested in liquid lead lithium eutectic. These steels, similar in microstructure and mechanical properties in the unirradiated condition were tested for their susceptibility to LME as function of temperature $\left(150-450^{\circ} \mathrm{C}\right)$ and strain rate $\left(1 \times 10^{-3}-1 \times 10^{-6} \mathrm{~s}^{-1}\right)$. Also, the influence of pre-exposure and surface stress concentrators was evaluated for both steels in, respectively, liquid PbBi and PbLi environment. To assess the LME effect, results of the tests in liquid metal environment are compared with tests in air or inert gas environment. Although both unirradiated and irradiated smooth ferritic-martensitic steels do not show any or little deterioration of mechanical properties in liquid lead alloy environment compared to their mechanical properties in gas as function of temperature and strain rate, pre-exposure or the presence of surface stress concentrators does lead to a significant decrease in total elongation for certain test conditions depending on the type of liquid metal environment. The results are discussed in terms of wetting enhanced by liquid metal corrosion or crack initiation processes.
\end{abstract}

(c) 2008 Elsevier B.V. All rights reserved.

\section{Introduction}

The nuclear reactor research sector has been interested in the use of liquid metals as a coolant for decades. However, recently this has been mostly focused on the application of heavy liquid metals more specifically lead alloys. Due to their excellent neutronic and thermodynamic properties $[1,2]$ and the absence of very high reactivity with water or air compared to liquid sodium, these alloys are considered to be very promising for the design of advanced nuclear systems.

In the ADS community, lead-bismuth eutectic is currently chosen to be both primary coolant and spallation source for the subcritical core of the XT-ADS [3]. On the other hand, within Fusion, one of the most promising

\footnotetext{
* Corresponding author. Tel.: +321433 3191; fax: +32 14321216. E-mail address: jvdbosch@sckcen.be (J. Van den Bosch).
}

designs for DEMO is foreseen to have liquid lead-lithium eutectic as tritium breeder [4].

Wherever the handling of liquid metals is required, issues such as liquid metal corrosion and liquid metal embrittlement need to be examined carefully. Although liquid metal embrittlement (LME) has been observed a long time ago, the mechanism is not yet fully understood due to the complexity of the phenomenon. Despite the fact that many interpretations of LME have been formulated [5-10], the prediction of its occurrence remains problematic. Moreover the concept of specificity of the solid metal-liquid metal couple has been questioned by several authors $[5,12,13]$ and various parameters such as metallurgical state, surface state, composition, solubility, temperature, strain rate, stress concentrators, etc. are known to influence the risk of LME [14-16].

Recently, several European groups, within both the FP5-MEGAPIE-TEST project [17] and the FP6-project EUROTRANS [18] have launched studies to assess the compatibility of the selected steel T91 with LBE. Although 
some experiments have shown that liquid lead alloys may reduce the performance of T91 in terms of total elongation [19-22], T91 does not show liquid metal embrittlement by LBE under all conditions $[16,23]$.

Compared to the efforts of the ADS community on the assessment of the mechanical behaviour of the structural materials in liquid LBE and lead, the fusion community has not fully assessed the possible risks of LME although one of the designs for DEMO is foreseen to have liquid lead lithium eutectic as tritium breeder. However, a few relevant papers of previous work on LME in PbLi showed some interesting results. Coen showed that no LME was found for stainless steel $316 \mathrm{~L}$ at temperatures close to the melting point of lead-lithium [25]. Tests with notched tensile specimens at $350^{\circ} \mathrm{C}$ under a constant uniaxial tensile load, below the engineering yield stress, however, have evidenced that many cracks filled with $\mathrm{Pb}$ and possibly $\mathrm{Li}$ were formed, not excluding a liquid metal embrittlement effect [26]. Borgstedt concluded that low cycle fatigue tests of martensitic steel showed no occurrence of LME [27]. A reduced life time for the martensitic steel during creep tests could only be observed for long exposure times, but was related to the reduced diameter of the specimens. Martensitic steels F82H-mod and OPTIFER IVb were tested in $\mathrm{P} 17 \mathrm{Li}$ at $250^{\circ} \mathrm{C}$ by Sample and it was shown that there was no LME in the tempered condition [28]. Tests of heat treated F82H-mod and OPTIFER IVb to simulate the heat affected zone of a weld show an LME susceptibility at $250{ }^{\circ} \mathrm{C}$, while increasing the test temperature up to $400{ }^{\circ} \mathrm{C}$ led to a recovery of the ductility. Post-weld heat treatment was sufficient to recover the mechanical properties. These results indicate that, similar to tests in LBE, LME in PbLi could be found when materials are in the hardened condition (HAZ) and when there is a stress concentrator (notch).

This paper describes a systematic study and comparison of the susceptibility to LME of the reduced activation ferritic-martensitic steel EUROFER97 in liquid lead lithium eutectic and of the susceptibility to LME of the commercial ferritic-martensitic T91 in liquid lead bismuth environment under controlled chemistry and well defined testing conditions.

\section{Experimental}

The tested T91 material was supplied by Ugine, France (heat 36224) as a hot rolled plate of $25 \mathrm{~mm}$ thickness in the normalized $\left(1040{ }^{\circ} \mathrm{C}\right.$ for $\left.60 \mathrm{~min}\right)$ and tempered $\left(760^{\circ} \mathrm{C}\right.$ for $60 \mathrm{~min})$ condition. The EUROFER97 was supplied by
FZK, Germany in the form of a forged bar with a diameter of $100 \mathrm{~mm}$. The material was normalised at $979^{\circ} \mathrm{C}$ for $1 \mathrm{~h}$ and $51 \mathrm{~min}$ followed by air cooling before a tempering treatment at $739^{\circ} \mathrm{C}$ for $3 \mathrm{~h}$ and $42 \mathrm{~min}$. Chemical compositions of both steels are given in Table 1. Both materials are $9 \mathrm{Cr}$ steels with a ferritic-martensitic microstructure having a very similar dislocation density. Their mechanical properties in the unirradiated condition are very similar when tested in gas [11].

Tensile tests in liquid metal environment were performed using small size cylindrical tensile samples machined in the $\mathrm{L}$ orientation (rolling direction). No surface treatments or modifications were made prior to testing.

The tests on non-irradiated T91 were performed using Liquid Metal Embrittlement Testing Station 1 (LIMETS 1) which allows controlled and clean LBE chemistry conditions [16], whereas the T91 irradiated in water was tested in a crucible filled with LBE placed inside one of the autoclaves otherwise used for testing active materials under PWR conditions [29]. The latter allowed less stringent control of the oxygen concentration due to the absence of an oxygen probe. However, by using the gas conditioning system to bubble through the liquid metal combined with a water vapour containing gas conditioning vessel we can state that the test conditions for the irradiated T91 samples were either low oxygen containing LBE or oxygen enriched LBE. All results in LBE on active material presented in this paper were obtained by testing in the low oxygen condition. Tests on non-irradiated specimens were performed in liquid metal containing between $10^{-6}$ and $10^{-7} \mathrm{wt} \%$ oxygen.

The LBE was delivered by Hetzel Metalle GmbH, Germany with a composition of $55.2 \mathrm{wt} \% \mathrm{Bi}$ and $44.8 \mathrm{wt} \% \mathrm{~Pb}$, $2 \mathrm{mg} / \mathrm{g} \mathrm{Cr}$ and less than $1 \mathrm{mg} / \mathrm{g} \mathrm{Ni}$.

EUROFER97 samples were all tested in liquid lead-lithium eutectic using Liquid Metal Embrittlement Testing Station 2 (LIMETS 2) which allows testing of both nonirradiated and irradiated materials in liquid metal environment under well controlled chemistry conditions [30,24].

The PbLi eutectic mixture (LLE) was prepared at SCK$\mathrm{CEN}$ by adding liquid lithium to liquid lead at a temperature of $400{ }^{\circ} \mathrm{C}$ under argon atmosphere. After sufficient mixing the melt was heated to $600{ }^{\circ} \mathrm{C}$ were it stayed for $2 \mathrm{~h}$. The mixture was cooled down and the eutectic temperature $\left(235^{\circ} \mathrm{C}\right)$ could be verified. Chemical analysis showed that the $\mathrm{Li}$ concentration was between 0.6 and $0.8 \mathrm{wt} \%$. $0.7 \mathrm{wt} \%$ of $\mathrm{Li}$ in the LLE mixture is equal to $17 \mathrm{at} \% \mathrm{Li}$. Several thermodynamic properties of $\mathrm{Pb}, \mathrm{Bi}, \mathrm{Li}, \mathrm{PbBi}$ and $\mathrm{PbLi}$ are given in Table 2.

Chemical composition of T91 and EEUROFER 97, wt $\%$

\begin{tabular}{|c|c|c|c|c|c|c|c|c|c|c|c|c|c|}
\hline & $\mathrm{C}$ & $\mathrm{Cr}$ & Mo & $\mathrm{W}$ & $\mathrm{Nb}$ & $\mathrm{Ta}$ & $\mathrm{V}$ & $\mathrm{P}$ & $\mathrm{Mn}$ & $\mathrm{Ni}$ & B & $\mathrm{N}$ & $\mathrm{Si}$ \\
\hline T91 & 0.10 & 8.32 & 0.96 & $<0.01$ & 0.06 & - & 0.24 & 0.02 & 0.43 & 0.24 & $<0.0005$ & 0.03 & 0.32 \\
\hline E97 & 0.12 & 8.96 & $<0.001$ & 1.1 & $<0.001$ & 0.13 & 0.19 & $<0.005$ & 0.43 & 0.007 & $<0.001$ & 0.016 & 0.07 \\
\hline
\end{tabular}


Table 2

Thermodynamical properties of lead $(\mathrm{Pb})$, lithium $(\mathrm{Li})$, lead-lithium eutectic and lead-bismuth eutectic

\begin{tabular}{|c|c|c|c|c|c|c|}
\hline Parameter & Units & $\mathrm{Pb}$ & $\mathrm{Li}$ & $\mathrm{Bi}$ & $\mathrm{Pb}-0.7 \mathrm{Li}$ & $\mathrm{Pb}-\mathrm{Bi}$ \\
\hline Atomic weight & $\mathrm{g} / \mathrm{mol}$ & 207.18 & 6.941 & 208.98 & 173.16 & 208.18 \\
\hline Neutron (th) absorption & Barn & 0.17 & - & & 12.3 & \\
\hline Melting temperature & ${ }^{\circ} \mathrm{C}$ & 327.4 & 180.69 & 271.0 & 235 & 123.5 \\
\hline Latent heat of melting & $\mathrm{kJ} / \mathrm{kg}$ & 23 & 0.00208 & 50.2 & 33.9 & 38.1 \\
\hline Volume change at melting & $\%$ & +3.5 & - & -3.32 & +3.5 & 0.0 \\
\hline Density $^{\mathrm{a}}$ & $\mathrm{kg} / \mathrm{m}^{3}$ & 10430 & $\sim 515$ & 9910 & 9150 & 10200 \\
\hline Thermal expansion $^{\mathrm{a}}$ & $1 / \mathrm{K}$ & $1.12 \times 10^{-4}$ & $0.56 \times 10^{-4}$ & & $1.23 \times 10^{-4}$ & \\
\hline Heat capacity $^{\mathrm{a}}$ & $\mathrm{J} / \mathrm{kg} / \mathrm{K}$ & 147 & & & 188 & 146.5 \\
\hline Thermal conductivity & $\mathrm{W} / \mathrm{m} / \mathrm{K}$ & 15.4 & 0.847 & 13.3 & 17.1 & 13.2 \\
\hline Kinetic viscosity $^{\mathrm{a}}$ & $\mathrm{m}^{2} / \mathrm{s}$ & $1.76 \times 10^{-7}$ & - & $1.42 \times 10^{-3}$ & $1.25 \times 10^{-7}$ & \\
\hline Surface tension $^{\mathrm{a}}$ & $\mathrm{N} / \mathrm{m}$ & 0.44 & 0.28 & & 0.43 & \\
\hline Solubility of $\mathrm{Fe}^{\mathrm{a}}$ & at. $\%$ & $2.72 \times 10^{-4}$ & - & & - & \\
\hline Boiling temperature & ${ }^{\circ} \mathrm{C}$ & 1745 & 1347 & 1490 & $\sim 1600$ & 1670 \\
\hline Latent heat of boiling & $\mathrm{kJ} / \mathrm{kg}$ & 860 & - & 855.2 & $\sim 900$ & 856.7 \\
\hline Saturation pressure & bar & $5.1 \times 10^{-6}$ & - & & $2 \times 10^{-8}$ & \\
\hline
\end{tabular}

${ }^{\mathrm{a}} T=500^{\circ} \mathrm{C}$.

\section{Results and discussion}

The mechanical properties of T91 and EUROFER97 in liquid lead alloy environment, being, respectively, liquid $\mathrm{PbBi}$ or $\mathrm{PbLi}$, were compared to their mechanical properties in inert gas environment as a function of strain rate. These tensile tests were performed at $245^{\circ} \mathrm{C}$ in the case of T91 and at $250{ }^{\circ} \mathrm{C}$ for the EUROFER 97 samples. Due to the small difference in testing temperature the results were plotted together in Fig. 1. In Fig. 1 the full symbols are results from tests of T91 and EUROFER97 in, respectively, $\mathrm{PbBi}$ (black) or $\mathrm{PbLi}$ (gray). For reasons of comparison the results in inert gas environment are shown as empty symbols. Although Fig. 1(A) shows relatively small variations in both yield strength and ultimate tensile strength as function of strain rate, these variations are considered to be insignificant and within the experimental scatter. The total elongation and uniform elongation, shown in Fig. 1(B), remain close to the same values although the elongations in the liquid metal environment remain little smaller for both T91 in PbBi and EUROFER97 in PbLi. Examination of fracture surfaces by scanning electron microscopy revealed fully dimpelled fracture surfaces on all examined specimens. Since tensile results are little or not dependent on strain rate as shown in Fig. 1 it allows us to compare tests performed on T91 and EUROFER97 as a function of temperature at different strain rates.

The mechanical behaviour of T91 and EUROFER97 as function of temperature is depicted in Fig. 2. Full symbols represent T91 tested in LBE at $5 \times 10^{-5} \mathrm{~s}^{-1}$. Empty symbols represent EUROFER97 tested in $\mathrm{PbLi}$ at $1 \times 10^{-4} \mathrm{~s}^{-1}$. The full and dashed lines in Fig. 2 were obtained by, respectively, fitting tensile data of the same batch of T91 tested in air or inert gas by several labs in Europe [16] and by fitting tensile data of EUROFER97 tested in air from the Fusion database [31]. Fig. 2(B) clearly shows that the uniform elongations of samples tested in liquid metals follow the expected trends very closely. All
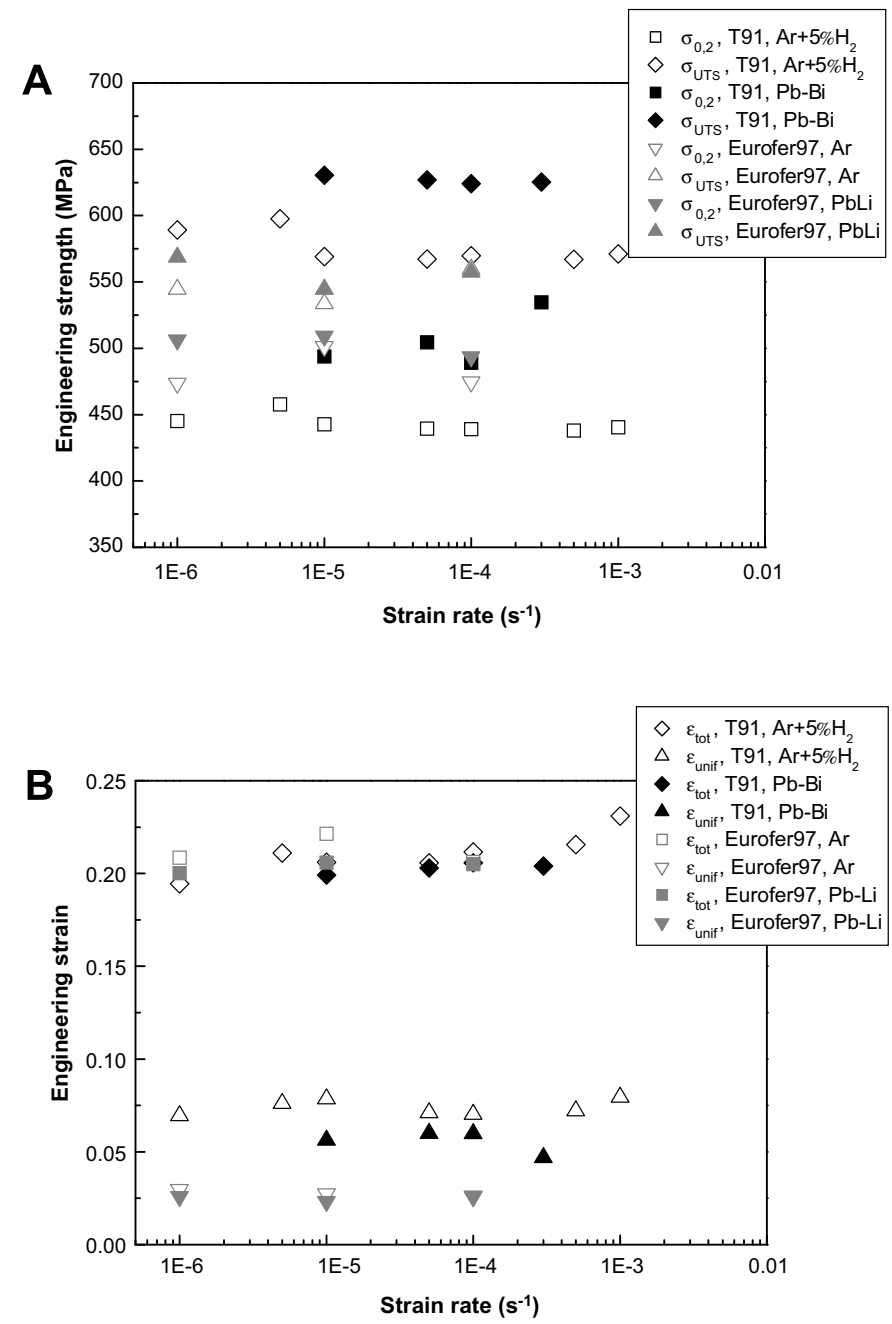

Fig. 1. Tensile results as function of strain rate. Full symbols for tests performed in liquid metal (T91 in PbBi; EUROFER97 in PbLi), empty symbols for tests performed in controlled gas atmosphere. Results on T91 at $245^{\circ} \mathrm{C}$ indicated in black, results on EEUROFER97 at $250{ }^{\circ} \mathrm{C}$ in dark gray. (A) Influence of the strain rate on the yield stress and the ultimate tensile strength; (B) influence of the strain rate on the uniform elongation and total elongation. 

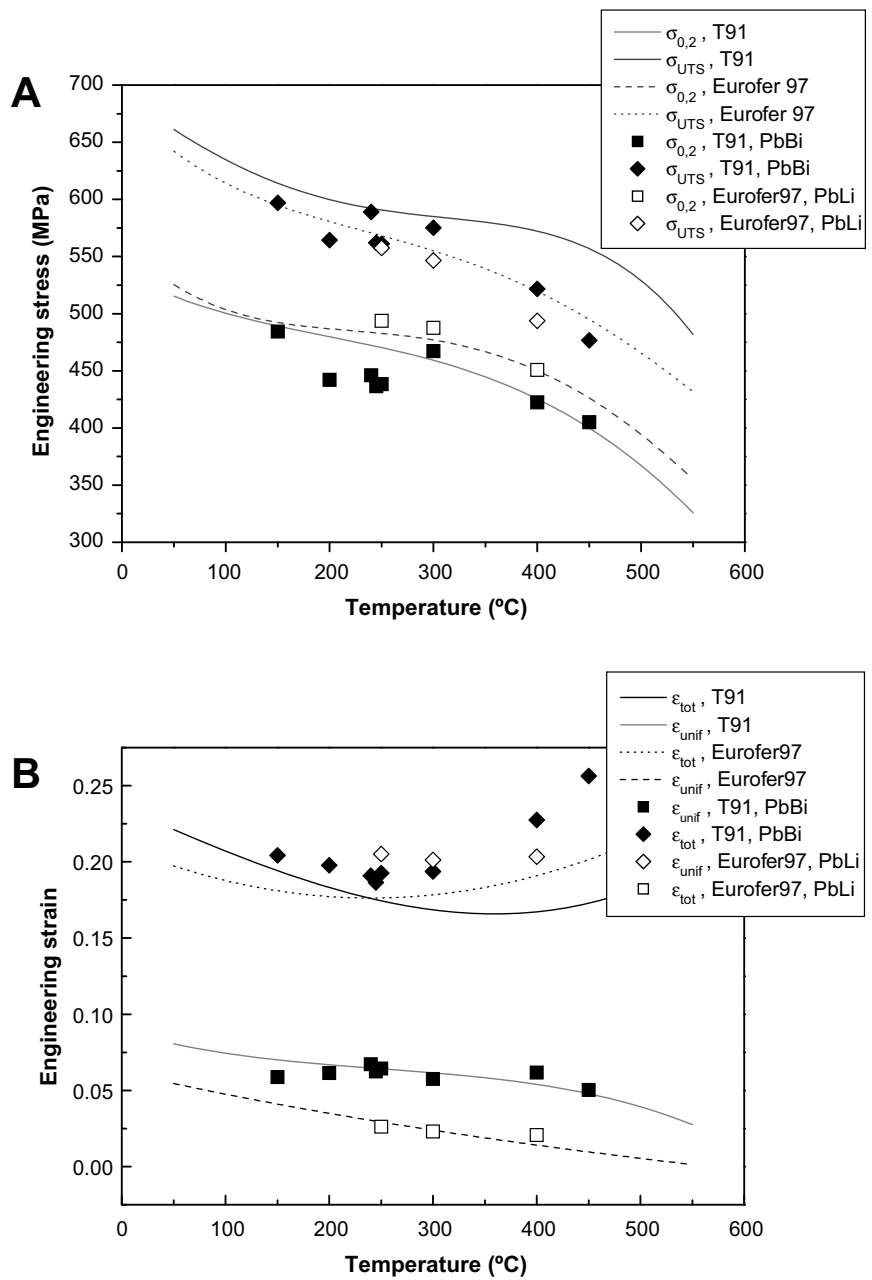

Fig. 2. Tensile results as function of temperature (strain rate: $5 \times 10^{-5} \mathrm{~s}^{-1}$ for T91; $1 \times 10^{-4} \mathrm{~s}^{-1}$ for EEUROFER97). Full symbols for tests of T91 in $\mathrm{PbBi}$, empty symbols for EEUROFER97 in PbLi. The lines are obtained from fitting to tensile data from tests in gas of, respectively, T91 and EEUROFER97. (A) Influence of temperature on the yield strength and tensile strength; (B) total and uniform elongation as a function of temperature.

results of total elongation in liquid metal for both T91 in $\mathrm{PbBi}$ and EUROFER97 in PbLi lie above the reference line. In case of any liquid metal embrittlement occurring the resulting total elongation would be significantly below this in air or inert gas under the same conditions. This is however, clearly not the case. These results seem contradictory to the ones mentioned earlier in the introduction [19-22,26], where LME was found under conditions of temperature and strain rate similar to those tested here. This is explained by the absence of intimate contact or wetting of the solid metal by the liquid metal and/or by the absence of initiated cracks in the outer surface of the solid. Surface cracks created by EDM cutting [23], liquid metal corrosion or plastic deformation at a machined notch [16] have shown to strongly increase the possible risk for LME. Apart from wetting and surface cracks it has also been shown from tests on heat treated material that an increase in hardness by thermal treatment also increases the risk for LME [32]. This led to believe that the increase in hardness of the material caused by neutron irradiation might also increase its susceptibility to LME. Fig. 3 shows the uniform and total elongation as function of irradiation dose of both neutron irradiated T91 and EUROFER97 tested in, respectively, $\mathrm{PbBi}$ and $\mathrm{PbLi}$ and compared to tests performed on these materials in Ar or air. Since the yield stress and ultimate tensile strength are known to remain close to the values in inert environment when tested in liquid metal even when LME occurs, those values are not shown here. Both materials were irradiated in contact with water prior to tensile testing in gas or liquid metal environment. Fig. 3(A) shows the tensile results of T91 irradiated in contact with water at $200{ }^{\circ} \mathrm{C}$ up to $4.36 \mathrm{dpa}$ and tested at $200^{\circ} \mathrm{C}$ using a strain rate of $5 \times 10^{-6} \mathrm{~s}^{-1}$. The empty symbols represent tests in air, whereas the full symbols represent tests in oxygen depleted LBE. Although some data points of total elongation are significantly below the reference line, examination of fracture surfaces did not reveal any brittle fracture mechanisms [29]. Fig. 3(B) shows the tensile results on EUROFER97 irradiated in water at $300^{\circ} \mathrm{C}$ up to $2.29 \mathrm{dpa}$ and tested at $300{ }^{\circ} \mathrm{C}$ in $\mathrm{PbLi}$ or Ar. Full symbols were obtained by tensile tests of EUROFER97 in PbLi environment, whereas the
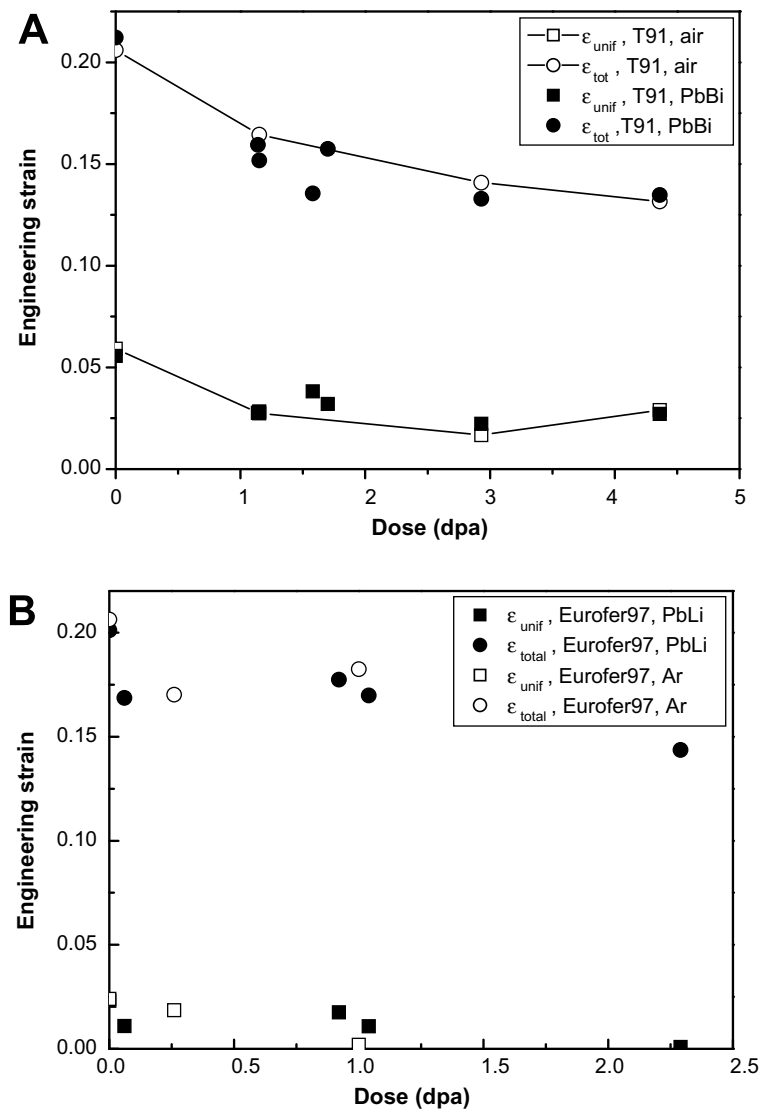

Fig. 3. Tensile results as function of irradiation dose. Full symbols for tests performed in liquid metal environment, empty symbols for tests in air or Ar. (A) total and uniform elongation of T91 irradiated at $200{ }^{\circ} \mathrm{C}$, tested at $200{ }^{\circ} \mathrm{C}$ as function of dose. (B) total and uniform elongation of EEUROFER97 irradiated and tested at $300{ }^{\circ} \mathrm{C}$ as function of dose. 
empty symbols represent tests performed in Ar environment. Unfortunately there is no reference test performed in $\mathrm{Ar}$ on a sample irradiated up to a dose of about $2.3 \mathrm{dpa}$ due to the restricted availability of samples at this dose. Furthermore total elongation values are geometry dependant and due to the different ratio of gauge length to diameter of the used samples compared to the other irradiated EUROFER97 samples for tensile testing it was not possible to compare the test in $\mathrm{PbLi}$ with reference values in Ar or air. Examination of fracture surfaces revealed fully ductile fracture surfaces for all specimens. Only a very small spot of brittle fracture could be found on the sample of 2.29 dpa [33]. Fig. 4 shows the SEM images of the fracture surface of the 2.29 dpa irradiated EUROFER97 sample. As can be seen in the overview of the fracture in Fig. 4(A) there is no obvious brittle fraction. However, as can be seen in Fig. 4(D) the fracture was not entirely ductile like Fig. 4(B) and (C).

Although up to now there is very limited data available on neutron irradiated material tested in contact with liquid metals, Fig. 3 shows that the effect of LME in certainly not predominant. It needs to be noted however, that these materials were irradiated in contact with water and therefore created a different type of oxide film as their native oxide layer or as they would have formed under irradiation in contact with liquid metals. The oxide layer formed under irradiation in contact with water might prevent sufficient wetting thus suppressing the increased susceptibility of the hardened material to LME. Although during SSRT testing the oxide layer is assumed to break due to its lower plasticity compared with the base material thus allowing intimate contact between the liquid metal and the underlying solid, it has been seen in SSRT testing of non active material that the kinetics of this breaking and wetting system are not allowing sufficient wetting to occur. To promote wetting to occur non-irradiated samples have been pre-exposed to either low oxygen $\mathrm{PbBi}$ or PbLi. This exposure is expected to corrode the native oxide layer of the sample and create intimate contact between the lead alloy and the base metal. As stated before [16], pre-exposure in low oxygen containing $\mathrm{PbBi}$ at $450^{\circ} \mathrm{C}$ for $4000 \mathrm{~h}$ caused one of two samples to be susceptible to LME however, the other sample did not show any effect. This was related to the fact that the non affected sample had an intact oxide layer, whereas clear evidence of corroded sites were found on the LME sample. In Fig. 5 the pre-exposed T91 sample is compared with a similar pre-exposed EUROFER 97 sample. However, in the case of the EUROFER97 the exposure was only for $1000 \mathrm{~h}$ at $470{ }^{\circ} \mathrm{C}$ and subsequent testing was done at $250^{\circ} \mathrm{C}$. As shown in Fig. 5(A) the LME has caused a significant decrease in total elongation by brittle fracture of part of the sample. Due to the reducing nature of the
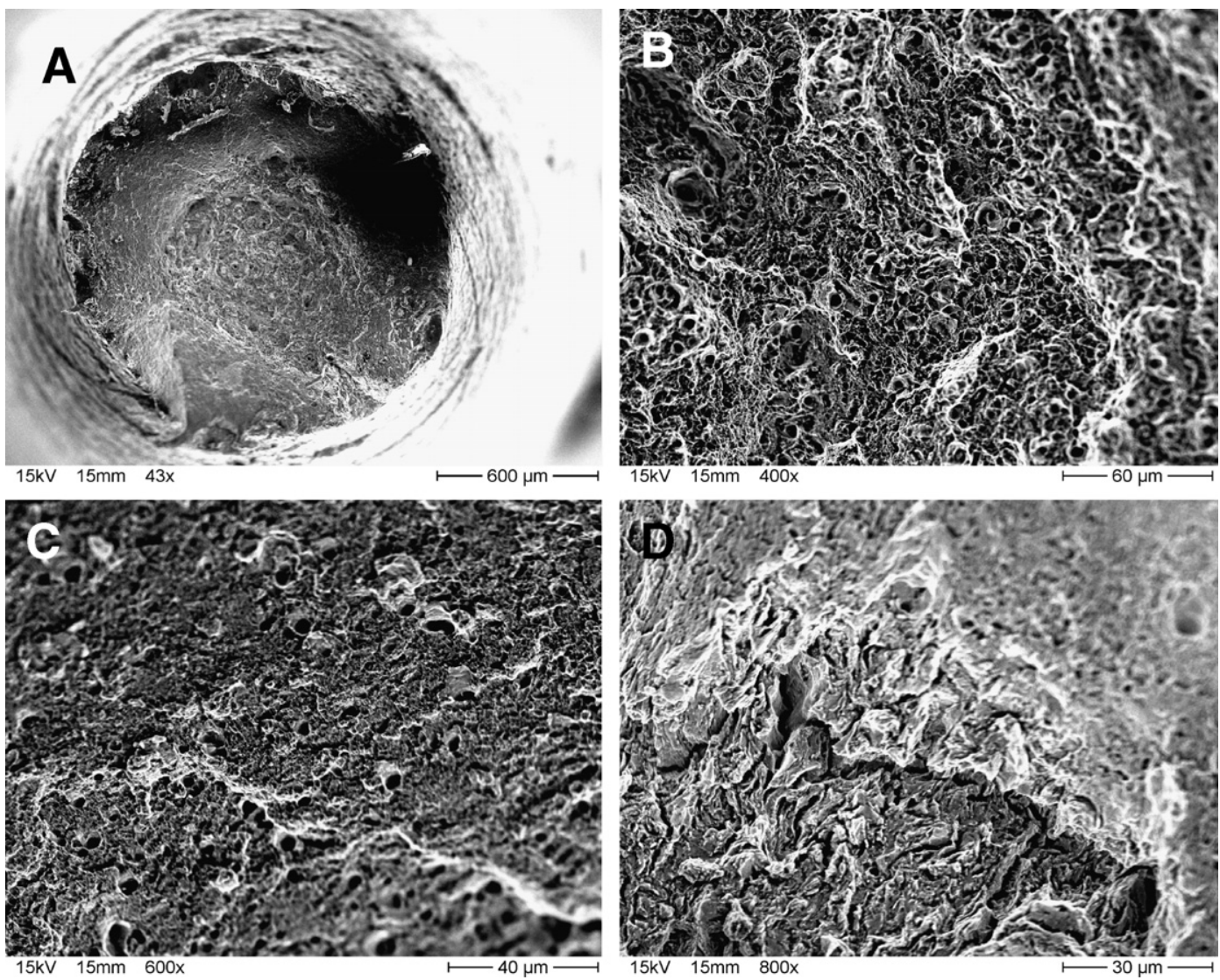

Fig. 4. SEM images of the fracture surface of EEUROFER97 irradiated up to $2.29 \mathrm{dpa}$ and tested in liquid PbLi environment. (A) Overview of the fracture surface. (B), (C) Ductile areas of the surface. (D) Zone showing brittle fracture aspects. 

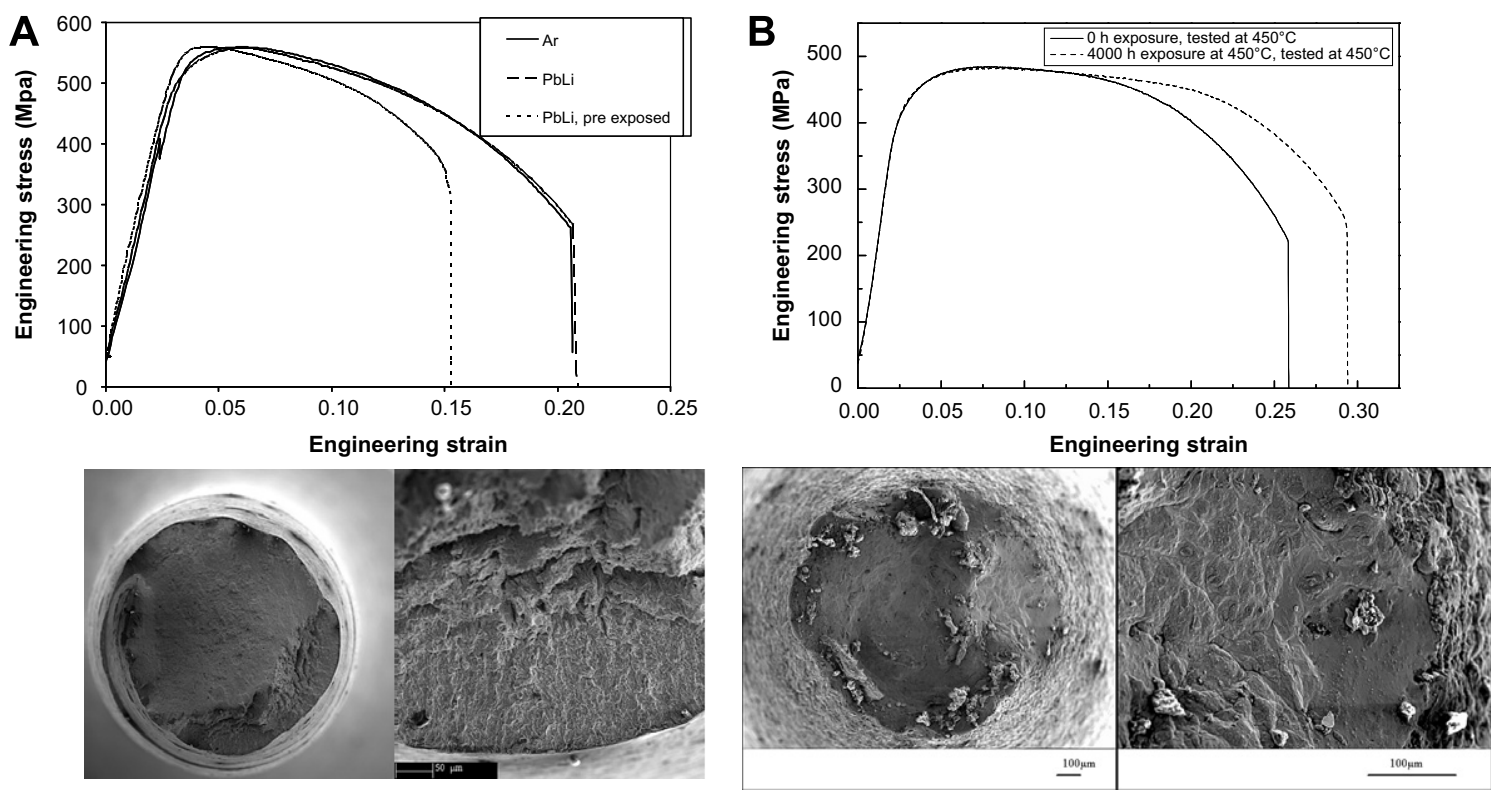

Fig. 5. Tensile curves and fracture surfaces of pre-exposed samples. (A) Tensile curves of EEUROFER97 tested in Ar and PbLi (without pre-exposure and pre-exposed for $1000 \mathrm{~h}$ in $\mathrm{PbLi}$ at $470{ }^{\circ} \mathrm{C}$ ) at $250^{\circ} \mathrm{C}, 1 \times 10^{-4} \mathrm{~s}^{-1}$. The fracture surface images were taken from the pre-exposed EEUROFER97 sample clearly showing a brittle fraction of the fracture surface. (B) Tensile curves of T91 tested in $\mathrm{PbBi}$ at $450{ }^{\circ} \mathrm{C}, 5 \times 10^{-5} \mathrm{~s}^{-1}$ without pre-exposure and after pre-exposure in $\mathrm{PbBi}$ for $4000 \mathrm{~h}$ at $450{ }^{\circ} \mathrm{C}$. The fracture surface images were taken from the pre-exposed sample tested at $450{ }^{\circ} \mathrm{C}$ clearly showing a brittle fraction of the surface.

$\mathrm{PbLi}$ mixture it is assumed that the native oxide layer was removed relatively faster compared to exposure in $\mathrm{PbBi}$ causing partial brittle fracture of the specimen. As seen in $\mathrm{PbBi}$, these corrosion sites are also assumed to function as initiated cracks [16]. Therefore the effect of machined notches was tested also for EUROFER97 samples in PbLi environment and compared to similar tests on T91 in PbBi.
Due to the sharp notch plastic deformation around the notch facilitates initiation of a crack at the surface resulting in fresh surface that can be wetted by the liquid metal. Fig. 6 however, shows that the notched sample tested in $\mathrm{PbLi}$ at $250^{\circ} \mathrm{C}$ using a strain rate of $1 \times 10^{-4} \mathrm{~s}^{-1}$ remains fully ductile, whereas the notched sample tested in $\mathrm{PbBi}$ at $200{ }^{\circ} \mathrm{C}$ using a strain rate of $5 \times 10^{-5} \mathrm{~s}^{-1}$ clearly shows
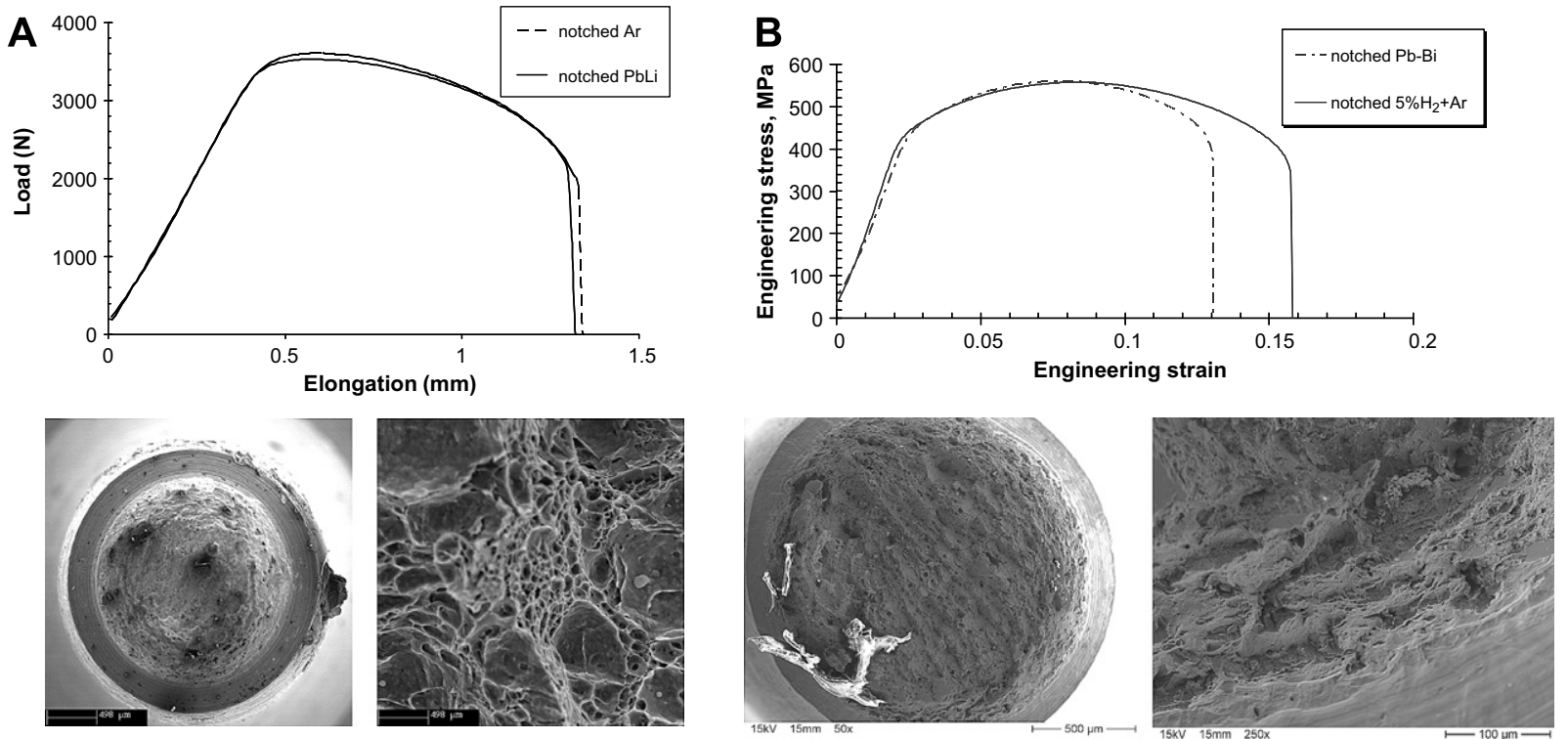

Fig. 6. Tensile curves and fracture surfaces of notched samples $\left(60^{\circ}\right.$ opening angle; notch radius $\left.<0.025 \mathrm{~mm}\right)$. (A) Tensile curves of notched EEUROFER97 tested in $\mathrm{Ar}$ and $\mathrm{PbLi}$ at $250^{\circ} \mathrm{C}, 1 \times 10^{-4} \mathrm{~s}^{-1}$. Fracture surface images were taken from the sample tested in $\mathrm{PbLi}$ showing the fully dimpled, thus ductile fracture. (B) Tensile curves of notched $\mathrm{T} 91$ tested in $\mathrm{Ar}+5 \% \mathrm{H}_{2}$ and $\mathrm{PbBi}$ at $200{ }^{\circ} \mathrm{C}, 5 \times 10^{-5} \mathrm{~s}^{-1}$. Fracture surface images were taken from the sample tested in $\mathrm{PbBi}$ showing the partly brittle fracture surface at the rim of the sample. 

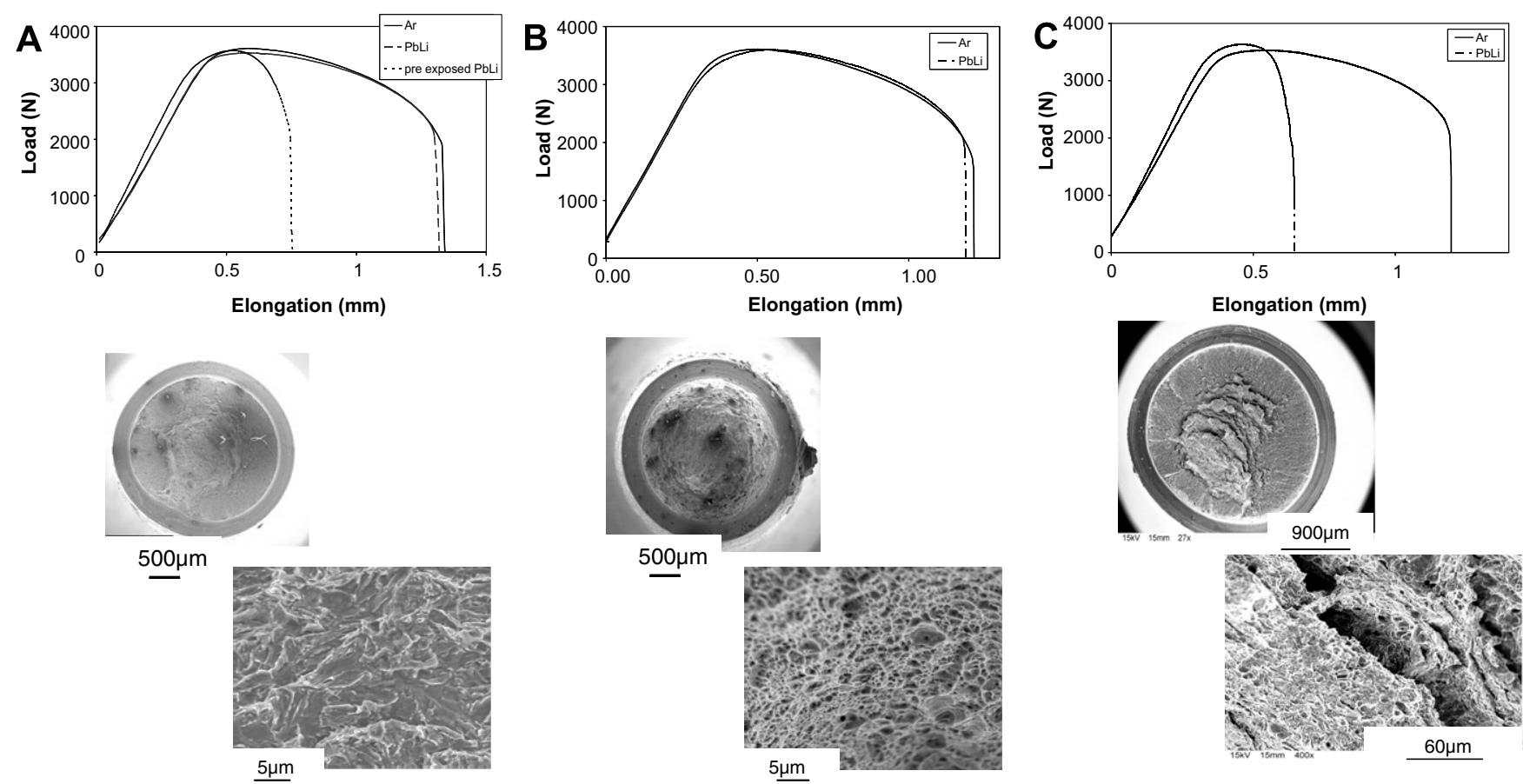

Fig. 7. Tensile curves and fracture surfaces of notched EEUROFER97 samples tested in Ar and PbLi at various strain rates without pre-exposure and after pre-exposure in $\mathrm{PbLi}$ at $470{ }^{\circ} \mathrm{C}$ for $1000 \mathrm{~h}$. (A) Tensile curves of EEUROFER97 samples tested at $250{ }^{\circ} \mathrm{C}, 1 \times 10^{-4} \mathrm{~s}^{-1}$ in $\mathrm{PbLi}$ with and without preexposure compared to tensile curve of notched EEUROFER97 at $250^{\circ} \mathrm{C}$ in Ar. Fracture surface images from the pre-exposed, notched sample are depicted, showing the significant brittle portion of the fracture surface. (B) Tensile curves of notched EEUROFER97 tested in Ar and PbLi at $250{ }^{\circ} \mathrm{C}$, $1 \times 10^{-5} \mathrm{~s}^{-1}$. Fracture surface images show the fully ductile fracture surface of the sample tested in PbLi. (C) Tensile curves of notched EEUROFER97 tested in $\mathrm{Ar}$ and $\mathrm{PbLi}$ at $250^{\circ} \mathrm{C}, 1 \times 10^{-6} \mathrm{~s}^{-1}$. Fracture surface images show the significant brittle portion of the fracture surface on the sample tested in PbLi.

LME and has brittle fracture aspects all around its fracture surface. The difference in behaviour of notched specimens and pre-exposed specimens in either $\mathrm{PbBi}$ or $\mathrm{PbLi}$ indicates that the predominant mechanism facilitating wetting is different in $\mathrm{PbBi}$ than in $\mathrm{PbLi}$ environment. It is clear that the measure of damage in which LME manifests when it occurs is very comparable in T91/PbBi and EUROFER97/PbLi. However, the circumstances leading to an occurrence of LME seem to be slightly different. The strongly reducing nature of lithium in the $\mathrm{PbLi}$ is thought to reduce the material surface sufficiently to facilitate wetting, whereas in $\mathrm{PbBi}$ environment a sufficient fraction of new, unoxidised surface needs to be formed by crack initiation on the outer surface in order to allow LME to occur. The fact that wetting of EUROFER97 in PbLi environment is controlled by liquid metal corrosion more than by crack initiation can be verified by increasing testing time. Tests as function of strain rate on smooth EUROFER97 specimens in PbLi as shown in Fig. 1 however, did not show any LME. Therefore it was thought that the crack initiation at the surface facilitated by a machined notch was of importance however, not the determining factor for LME in PbLi. Fig. 7 shows a comparison of tests on notched EUROFER97 samples. Fig. 7(A) shows the results of a pre-exposed sample $\left(1000 \mathrm{~h}\right.$ in $\mathrm{PbLi}$ at $\left.470{ }^{\circ} \mathrm{C}\right)$ tested at $250{ }^{\circ} \mathrm{C}$ using a strain rate of $1 \times 10^{-4} \mathrm{~s}^{-1}$. Fig. 7(B) shows a non exposed notched EUROFER97 sample tested at $250{ }^{\circ} \mathrm{C}$ using a strain rate of $1 \times 10^{-5} \mathrm{~s}^{-1}$ and Fig. 7(C) shows a notched non exposed sample of EUROFER97 tested at $250^{\circ} \mathrm{C}$ using a strain rate of $1 \times 10^{-6} \mathrm{~s}^{-1}$. It is clear that both the pre-exposed notched EUROFER97 and the non exposed notched sample tested in PbLi at $1 \times 10^{-6} \mathrm{~s}^{-1}$ show clear evidence of LME, whereas the notched sample tested in $\mathrm{PbLi}$ at $1 \times 10^{-5} \mathrm{~s}^{-1}$ does not. Testing the used sample geometry at a strain of $1 \times 10^{-6} \mathrm{~s}^{-1}$ corresponds with a testing period of about 30 days. This is comparable with an exposure time of $1000 \mathrm{~h}$. Results shown in Fig. 7 clearly support the importance of liquid metal corrosion in PbLi to facilitate wetting and allowing LME to occur in EUROFER97.

\section{Conclusions}

The susceptibility to LME in lead alloys was assessed and compared for the two currently most important candidate structural steels for ADS and Fusion being, respectively, the commercial ferritic-martensitic T91 and the reduced activation ferritic-martensitic EUROFER97. The objective of this work is to compare the risk of occurrence of LME for T91 and EUROFER97 steels in PbBi and $\mathrm{PbLi}$, respectively, in a wide range of operative conditions.

The untreated steels are protected from LME in both lead alloys by their native oxide layers. No embrittlement or decrease of mechanical properties of smooth untreated 
material was found by varying strain rate or test temperature. Irradiation hardening caused by neutron irradiation in water does not significantly increase the susceptibility to LME of T91 in PbBi nor of EUROFER97 in PbLi. When it occurs LME in lead alloys leads to a significant decrease in total elongation while yield stress and ultimate tensile strength of the material remain the same. Exposure to liquid metal and thus liquid metal corrosion plays an important role in the increase of the risk to LME. In PbBi environment the initiation of a crack by means of corrosion or surface defects facilitates wetting and thus increases the susceptibility to LME. In PbLi the reducing influence of the $\mathrm{Li}$ increases the reducing effect of the liquid metal environment and liquid metal corrosion facilitates wetting thus leading to LME. Presence of a surface crack also has influence in $\mathrm{PbLi}$ environment however, its influence is smaller than this of the wetting caused by liquid metal corrosion.

\section{References}

[1] K. Morita, W. Mashek, M. Flad, H. Yamano, Y. Tobita, Nucl. Sci. Technol. 43 (5) (2006) 526.

[2] V. Sobolev, MYRRHA ADS Database: Part I. Thermophysical Properties of Molten Lead-Bismuth Eutectic, SCK-CEN Report, BLG-1014, 2005.

[3] H. Ait Abderrahim, P. Kupschus, E. Malambu, Ph. Benoit, K. Van Tichelen, B. Arien, F. Vermeersch, P. D'hondt, Y. Jongen, S. Ternier, D. Vandeplassche, Nucl. Instrum. Meth. A 463 (2001) 487.

[4] L.V. Boccaccini, L. Giancarli, G. Janeschitz, S. Hermsmeyer, Y. Poitevin, A. Cardella, E. Diegele, J. Nucl. Mater. 329-333 (Part 1) (2004) 148.

[5] M.H. Kamdar, Prog. Mater. Sci. 15 (1973) 289.

[6] N.S. Stoloff, in: M.H. Kamdar (Ed.), Embrittlement by Liquid and Solid Metals, 1982, p. 3.

[7] P.J.L. Fernandes, D.R.H. Jones, Int. Mater. Rev. 42 (1997) 251.

[8] B. Joseph, M. Picat, F. Barbier, Eur. Phys. J.: Appl. Phys. 5 (1999) 19.

[9] A.R.C. Westwood, C.M. Preece, M.H. Kamdar, In: Adsorption Induced Brittle Fracture in Liquid Environments, vol. 3, Academic Press, 1971, p. 589.

[10] V.V. Popovich, I.G. Dmukhovskaya, Sov. Mater. Sci. 365 (1978).

[11] M. Matijasevic, E. Lucon, A. Almazouzi, Behavior of ferritic/ martensitic steels after n-irradiation at $200{ }^{\circ} \mathrm{C}$ and $300{ }^{\circ} \mathrm{C}$, J. Nucl. Mater., this issue.
[12] P.J.L. Fernandes, D.R.H. Jones, Eng. Fail. Anal. 3 (1996) 299.

[13] A. Legris, G. Nicaise, J.-B. Vogt, J. Foct, D. Gorse, D. Vancon, Scripta Mater. 43 (2000) 997.

[14] W. Rostoker, J.M. McCoughy, M. Markus, in: Embrittlement by Liquid Metals, Reinhold, Chapman and Hall, New York, London, UK, 1960.

[15] B. Joseph, M. Picat, F. Barbier, Eur. Phys. J. AP 5 (1999) 19.

[16] J. Van den Bosch, D. Sapundjiev, A. Almazouzi, J. Nucl. Mater. 356 (2006) 237.

[17] H. Glasbrenner, F. Gröschel, J. Nucl. Mater. 335 (2004) 239.

[18] FP6-EUROpean Research Programme for the TRANSmutation of High Level Nuclear Waste in an Accelerator Driven System, Contract No. FI6W-CT-2004-516520 (www.eurotrans.de).

[19] T. Auger, G. Lorang, S. Guerin, J.-L. Pastol, D. Gorse, J. Nucl. Mater. 335 (2004) 227.

[20] G. Nicaise, A. Legris, J.B. Vogt, J. Foct, J. Nucl. Mater. 296 (2001) 256.

[21] S. Guerin, J.-L. Pastol, C. Leroux, D. Gorse, J. Nucl. Mater. 318 (2003) 339.

[22] A. Aiello, M. Agostini, G. Benamati, B. Long, G. Scaddozzo, J. Nucl. Mater. 335 (2004) 217.

[23] Y. Dai, B. Long, F. Groeschel, J. Nucl. Mater. 356 (2006) 222.

[24] R.W. Bosch, S. Van Dyck, A. Al Mazouzi, Investigation of the susceptibility of EUROFER97 in lead-lithium to liquid metal embrittlement (LME), Fusion Eng. Des. (2007), doi:10.1016/ j.fusengdes.2007.04.006.

[25] V. Coen, A. Fenici, H. Kolbe, L. Orecchia, T. Sasaki, J. Nucl. Mater. 110 (1982) 108

[26] V. Coen, H. Kolbe, L. Orecchia, J. Nucl. Mater. 155-157 (1988) 740.

[27] H.U. Borgstedt, G. Frees, M. Grundmann, Z. Peric, Fusion Eng. Des. 14 (1991) 329.

[28] T. Sample, H. Kolbe, J. Nucl. Mater. 283-287 (2000) 1336.

[29] D. Sapundjiev, A. Al Mazouzi, S. Van Dyck, J. Nucl. Mater. 356 (2006) 229

[30] R.W. Bosch, A. Almazouzi, D. Sapundjiev, H. Dekien, Development of a hot cell test set-up for liquid metal embrittlement (LME) studies in lead-lithium and lead-bismuth, HotLab 2005, Petten, The Netherlands, 2005.

[31] E. Lucon, Characterisation of the Mechanical Properties of EUROFER in the Unirradiated and Irradiated Condition, SCK-CEN-BLG945, 2003

[32] I. Serre, J.-B. Vogt, Nucl. Eng. Des. 237 (2007) 677.

[33] R.W. Bosch, S. Van Dyck, A. Al Mazouzi, Liquid Metal Embrittlement (LME) of Fusion Materials in Pb17Li, SCK-CEN-R-4464, 2007. 